\title{
Análise multivariada da divergência genética de genótipos de arroz sob estresse salino durante a fase vegetativa ${ }^{1}$
}

\author{
Multivariate analysis of genetic divergence of genotypes of rice under salt stress \\ during the vegetative phase
}

\author{
Letícia Carvalho Benitez ${ }^{2 *}$, Isabel Corrêa da Silva Rodrigues ${ }^{2}$, Luis Willian Pacheco Arge², Márcia Vaz Ribeiro² \\ e Eugenia Jacira Bolacel Braga ${ }^{3}$
}

\begin{abstract}
Resumo - A salinidade, dos solos e da água de irrigação, constitui fator limitante para o cultivo do arroz, principalmente nos estágios iniciais do desenvolvimento e no período de floração. A utilização de fontes de água de má qualidade para irrigação resulta no acúmulo de sais no solo, causando toxicidade importante na cultura. Uma solução para o problema seria a introdução de variedades com tolerância à salinidade elevada. Assim, objetivou-se com este trabalho avaliar a divergência genética entre genótipos de arroz visando à seleção de genótipos tolerantes à salinidade durante a fase vegetativa. Sementes de 10 genótipos de arroz foram cultivadas in vitro, em meio MS acrescido de 0 e $136 \mathrm{mM}$ de $\mathrm{NaCl}$. Após 21 dias, foram avaliados seis caracteres morfológicos e os resultados submetidos a análises multivariadas. Os métodos de otimização de Tocher, baseado na distância de Mahalanobis, e a dispersão gráfica das variáveis canônicas seguiram a mesma tendência de agrupamento dos genótipos, formando seis grupos distintos. A característica massa fresca da parte aérea foi a que mais contribuiu para a dissimilaridade genética entre os genótipos, pelo método de Singh, enquanto as duas primeiras variáveis canônicas foram suficientes para explicar $91,27 \%$ da variação observada. Nas condições experimentais testadas, os genótipos apresentaram graus distintos de tolerância à salinidade, sendo BRS Colosso, BRS Bojuru e BR IRGA 410, pertencentes aos grupos três e quatro, os que se mostraram mais tolerantes ao estresse salino e o genótipo Moti, pertencente ao grupo dois, o que se mostrou mais sensível.
\end{abstract}

Palavras-chave - Variáveis canônicas. Métodos de agrupamento. Oryza sativa L. Salinidade.

\begin{abstract}
Soil salinity is a limiting factor for rice cultivation, especially in the early stages of development and the flowering period. The use of sources of poor quality water for irrigation results in the accumulation of salts in the soil, causing major toxicity in culture. A solution to the problem would be the introduction of varieties with tolerance to high salinity. Hus the aim of this work is to evaluate genetic divergence among rice genotypes, aiming at the selection of genotypes tolerant to salinity during the vegetative phase. Seeds of 10 rice genotypes were grown in vitro on MS medium supplemented with 0 and $136 \mathrm{mM} \mathrm{NaCl}$. After 21 days, six morphological characters were evaluated and the results subjected to multivariate analysis. The methods of Tocher, based on Mahalanobis distance, and graphic dispersion of canonic variables followed the same pattern of clustering structure, forming six groups. The characteristic of shoot fresh weight was the largest contributor to the genetic dissimilarity between genotypes by the method of Singh, while the other two canonic variables were sufficient to account for $91.27 \%$ of observed variation. Under the experimental conditions tested, the genotypes showed different degrees of salinity tolerance, while Colossus BRS, BRS Bojuru and BR IRGA 410, belonging to the groups three and four, were those who were more tolerant genotype and Moti, belonging to two what was more sensitive to salt stress.
\end{abstract}

Key words - Canonical variables. Cluster analysis. Oryza sativa L. Salinity.

\footnotetext{
* Autor para correspondência

'Recebido para publicação em 31/08/2010; aprovado em 31/01/2011

Trabalho submetido e selecionado no primeiro Simpósio Brasileiro de Salinidade realizado de 12-15/10/2010 em Fortaleza, Ceará, Brasil; Pesquisa desenvolvida junto a Universidade Federal de Pelotas; tema de Tese financiada pela CAPES

${ }^{2}$ Programa de Pós-Graduação em Fisiologia Vegetal, Departamento de Botânica, Universidade Federal de Pelotas, Campus Capão do Leão, Caixa Postal 354, Pelotas-RS, Brasil, 96.010-900, lecbenitez@gmail.com

${ }^{3}$ Departamento de Botânica, Universidade Federal de Pelotas, Campus Capão do Leão, Caixa Postal 354, Pelotas-RS, Brasil, 96.010-900, eugenia@ufpel.tche.br
} 


\section{Introdução}

O arroz (Oryza sativa L.) é uma planta da família Poaceae, monocotiledônea da ordem Poales, cuja duração do ciclo da planta, de semente a semente, varia de 80 a 280 dias, dependendo da variedade (MARCONDES; GARCIA, 2009). Este cereal apresenta considerável valor econômico, sendo a principal fonte de alimentação para dois terços da população mundial, com grande influência no desenvolvimento sócio-econômico. Os maiores produtores mundiais de arroz são China, índia e Indonésia. No Brasil, os maiores produtores nacionais são o Rio Grande do Sul e Santa Catarina, os quais produziram $69,8 \%$ da safra do cereal no País em 2008 (CONAB, 2008).

No Rio Grande do Sul, o principal sistema de irrigação da cultura do arroz é por inundação, podendo conduzir, com o tempo, à salinização dos solos que possuem drenagem inadequada, impedindo a remoção do sal por lixiviação (MACEDO et al., 2010).

A salinidade dos solos e da água de irrigação é considerada um dos principais fatores abióticos responsável pelo estresse nas plantas, causando danos no metabolismo vegetal, reduzindo a produtividade agrícola e provocando efeitos deletérios em muitos processos fisiológicos (MUNNS, 2002).

O excesso de sais pode alterar tanto as funções fisiológicas quanto bioquímicas das plantas, causando estresse osmótico, o que resulta em distúrbios das relações hídricas, alterações na absorção e utilização de nutrientes essenciais, além do acúmulo de íons tóxicos (AMORIN et al., 2010).

No Brasil, cerca de quatro milhões de hectares de terras são afetadas por sais, as quais proporcionam baixa produtividade (SZABOLCS, 1989). No Rio Grande do Sul, a ocorrência solos salinos se restringe às áreas de influência de sedimentos marinhos e/ou de contato com águas salinas, sendo mais frequentes em áreas planas e na Planície Costeira, além da região da Laguna dos Patos, Taim, Mangueira e Bojuru, situadas na região Sul do Estado (BISSANI et al., 2008). Esta situação faz com que o uso de genótipos tolerantes à salinidade seja fator importante à viabilidade de produção de alimentos.

Na busca por cultivares superiores, a utilização da variabilidade genética nos cruzamentos de grupos geneticamente divergentes representa uma importante estratégia para obter ganhos de seleção. A importância da diversidade genética para o melhoramento reside no fato de fornecer parâmetros para a identificação de genótipos superiores, uma vez que a escolha de genitores para formação de populações segregantes é uma das principais decisões que o melhorista precisa tomar (BERTAN et al., 2006).
Neste contexto, a utilização de técnicas multivariadas é uma opção viável para esta finalidade, uma vez que permite múltiplas combinações de informações dentro da unidade experimental (MOREIRA et al., 2009). Vários métodos multivariados podem ser usados na predição da diversidade genética. Entre essas técnicas, as mais empregadas são: a análise por componentes principais, a análise por variáveis canônicas e os métodos de agrupamento, cuja aplicação depende da utilização de uma medida de dissimilaridade previamente estimada (OLIVEIRA et al., 2003). A escolha baseia-se na precisão desejada pelo pesquisador, bem como na facilidade da análise e na forma como os dados foram obtidos (BEZERRA NETO et al., 2010).

Vários trabalhos que avaliam a diversidade e a divergência genética utilizando-se caracteres morfoagronómicos e marcadores moleculares foram realizados nos últimos anos (BERTINI et al., 2010). Por exemplo, Sudré et al. (2006) avaliaram a divergência genética entre acessos de Capsicum spp. e verificaram a eficiência da utilização de variáveis multicategóricas na discriminação de genótipos. Coimbra et al. (2010), trabalhando com análises multivariadas, realizaram a caracterização e divergência genética de populações de milho do Sudeste de Minas Gerais e, Bertini et al. (2010) estudaram a divergência genética entre genótipos de coentro.

Diante da importância econômica que a cultura do arroz assume em âmbito regional e nacional, a avaliação da diversidade genética de populações, para o caráter tolerância à salinidade, permitirá o conhecimento das melhores combinações híbridas, viabilizando a obtenção de genótipos superiores nas gerações segregantes. Neste trabalho objetivou-se avaliar a divergência genética, quanto à tolerância ao sal, entre genótipos de arroz, através de técnicas multivariadas.

\section{Material e métodos}

O experimento foi conduzido no Laboratório de Cultura de Tecidos pertencente ao Departamento de Botânica, Instituto de Biologia da Universidade Federal de Pelotas (UFPEL), localizado no município de Pelotas-RS.

Foram utilizados 10 genótipos de arroz (Oryza sativa L.), sendo cinco pertencentes ao grupo índica (BR IRGA416, BR IRGA 418, BR IRGA 417, BR IRGA 410, BR IRGA 409) e cinco, ao grupo japônica (BRS Colosso, Moti, Oro, BRS Bojuru e Talento).

Em câmara de fluxo laminar, as sementes foram colocadas para germinar em tubos de ensaio contendo $5 \mathrm{~mL}$ de meio MS (MURASHIGE; SKOOG, 
1962), com metade da concentração das fontes de sais, suplementado com $20 \mathrm{~g} \mathrm{~L}^{-1}$ de sacarose, $100 \mathrm{mg} \mathrm{L}^{-1} \mathrm{de}$ mio-inositol e solidificado com a adição de $6 \mathrm{~g} \mathrm{~L}^{-1}$ de ágar. As plântulas permaneceram em sala de crescimento durante 21 dias, com um fotoperíodo de 16 horas e densidade de fluxo luminoso de $25 \mu \mathrm{mol} \mathrm{m}^{-2} \mathrm{~s}^{-1}$.

Os tratamentos foram constituídos por duas concentrações de $\mathrm{NaCl}$ acrescidos ao meio de cultura. As concentrações utilizadas foram 0 (testemunha) e $136 \mathrm{mM}\left(8 \mathrm{~g} \mathrm{~L}^{-1}\right)$ de $\mathrm{NaCl}$. Após o preparo de cada meio o $\mathrm{pH}$ destes foi ajustado para 5,8. Em seguida, os meios foram distribuídos nos tubos de ensaio, os quais foram fechados com algodão e alumínio e autoclavados a $121^{\circ} \mathrm{C}$, durante 20 minutos.

O delineamento experimental utilizado foi o inteiramente casualizado com cinco repetições por tratamento, sendo cada uma delas representada por cinco tubos, contendo uma semente cada. Após 21 dias, as plântulas foram avaliadas quanto às características morfológicas: altura da parte aérea $(\mathrm{cm})$, número de folhas, comprimento da raiz $(\mathrm{cm})$, número de raízes e massa fresca da parte aérea e do sistema radicular (g). Para esses caracteres foram realizados cálculos percentuais de desempenho relativo (aumento ou redução), considerando-se $100 \%$ o valor absoluto do tratamento controle $(0 \mathrm{mM}$ de $\mathrm{NaCl})$, com a finalidade de observar o comportamento diferencial dos genótipos frente ao estresse.

As medidas de dissimilaridade foram determinadas segundo o modelo de análise multivariada, permitindo a obtenção das matrizes de dissimilaridade, de covariância residual e das médias dos genótipos. Posteriormente, foram determinadas as variáveis canônicas, conforme relatado por Rao (1952), com o propósito de identificar genótipos similares em gráfico de dispersão bi ou tridimensional. Foi aplicado o método de agrupamento de otimização de Tocher (CRUZ; CARNEIRO, 2003), utilizando a distância generalizada de Mahalanobis $\left(\mathrm{D}^{2}\right)$ como medida de dissimilaridade. Utilizou-se, também, o critério de Singh (1981) para quantificar a contribuição relativa dessas características para a divergência genética. As análises foram realizadas utilizando o programa computacional Genes, versão 2007 (CRUZ, 2007).

\section{Resultados e discussão}

As medidas de dissimilaridade genética (TAB. 1), estimadas a partir da distância de Mahalanobis $\left(\mathrm{D}^{2}\right)$, apresentaram uma magnitude de 3,90 a 351,90, indicando a presença de ampla variabilidade genética para tolerância à salinidade entre os genótipos estudados.

A combinação entre BRS Colosso e Moti foi a mais divergente $\left(\mathrm{D}^{2}=351,90\right)$, seguida pela combinação entre BRS Colosso e Talento $\left(\mathrm{D}^{2}=309,84\right)$, enquanto a menor distância foi obtida entre os genótipos BR IRGA 418 e Oro $\left(D^{2}=3,90\right)$, seguida pelo par Moti e Talento $\left(\mathrm{D}^{2}=16,42\right)$. É interessante salientar que entre as maiores distâncias encontradas, o genótipo Moti esteve presente em praticamente todas as combinações, mostrando-se um genótipo bastante divergente dos demais.

Tabela 1 - Matriz de dissimilaridade com base na distância de Mahalanobis $\left(\mathrm{D}^{2}\right)$ entre 10 genótipos de arroz, submetidos à concentração de $136 \mathrm{mM} \mathrm{NaCl}$

\begin{tabular}{|c|c|c|c|c|c|c|c|c|c|c|}
\hline *Genótipos & 1 & 2 & 3 & 4 & 5 & 6 & 7 & 8 & 9 & 10 \\
\hline 1 & 0 & & & & & & & & & \\
\hline 2 & 42,13 & 0 & & & & & & & & \\
\hline 3 & 351,90 & 167,37 & 0 & & & & & & & \\
\hline 4 & 77,02 & 20,85 & 114,70 & 0 & & & & & & \\
\hline 5 & 165,29 & 49,94 & 37,11 & 26,81 & 0 & & & & & \\
\hline 6 & 18,31 & 35,08 & 318,16 & 72,89 & 138,86 & 0 & & & & \\
\hline 7 & 86,91 & 34,18 & 111,18 & 3,90 & 29,41 & 84,98 & 0 & & & \\
\hline 8 & 38,16 & 23,65 & 241,83 & 52,19 & 98,13 & 41,62 & 71,08 & 0 & & \\
\hline 9 & 42,53 & 19,55 & 202,81 & 27,27 & 67,86 & 19,08 & 36,95 & 30,63 & 0 & \\
\hline 10 & 309,84 & 141,15 & 16,42 & 89,98 & 26,96 & 261,09 & 92,08 & 192,58 & 149,87 & 0 \\
\hline
\end{tabular}

*(1) BRS Colosso, (2) BR IRGA 416, (3) Moti, (4) BR IRGA 418, (5) BR IRGA 417, (6) BR IRGA 410, (7) Oro, (8) BR IRGA 409, (9) BRS Bojuru, (10) BRS Talento 
A técnica multivariada de quantificação da distância de Mahalanobis $\left(\mathrm{D}^{2}\right)$ permite quantificar a importância relativa de caracteres para a diversidade genética por meio da avaliação da contribuição destes para os valores de $\mathrm{D}^{2}$. Neste experimento, ao verificar a contribuição relativa de cada variável no tocante a dissimilaridade genética, foi identificada variabilidade entre os caracteres analisados.

O parâmetro morfológico que apresentou a maior variação, por conseguinte, aquele que apresentou maior contribuição para a divergência entre os genótipos foi massa fresca da parte aérea, o qual contribuiu com $50,8 \%$ para divergência total, enquanto que a variável massa fresca do sistema radicular e número de raízes contribuíram juntas com 32,3\% (TAB. 2). Estes resultados reforçam os obtidos por Benitez et al. (2010), os quais, ao investigar a contribuição relativa de cada variável para a dissimilaridade genética entre genótipos de arroz cultivados in vitro, observaram que as variáveis massa fresca da parte aérea e de raiz foram os caracteres morfológicos que mais contribuíram para a divergência entre os genótipos.

Assim, entre as características estudadas, estas são as mais eficientes para explicar a dissimilaridade entre os genótipos, devendo ser priorizadas em estudos de dissimilaridade cujo objetivo seja verificar a tolerância de genótipos de arroz submetidos à salinidade em cultivo in vitro.

Tabela 2 - Contribuição relativa dos caracteres morfológicos para a dissimilaridade genética de 10 genótipos de arroz cultivados in vitro, em meio MS acrescido de $136 \mathrm{mM} \mathrm{NaCl}$, pelo método proposto por SINGH (1981), em ordem crescente de importância

\begin{tabular}{|c|c|c|}
\hline $\begin{array}{c}\text { Caracteres } \\
\text { Morfológicos }\end{array}$ & $\mathrm{Sj}^{1}$ & $\begin{array}{l}\text { Contribuição } \\
\text { Relativa (\%) }\end{array}$ \\
\hline $\begin{array}{l}\text { Massa fresca } \\
\text { da parte aérea } \\
(\mathrm{g})\end{array}$ & 2175,141809 & 50,8112 \\
\hline $\begin{array}{c}\text { Massa fresca } \\
\text { do sistema } \\
\text { radicular }(\mathrm{g})\end{array}$ & 692,92746 & 16,1868 \\
\hline $\begin{array}{l}\text { Número de } \\
\text { raiz }\end{array}$ & 690,206907 & 16,1232 \\
\hline $\begin{array}{l}\text { Comprimento } \\
\text { da raiz } \\
\text { principal }(\mathrm{cm})\end{array}$ & 336,401794 & 7,8583 \\
\hline $\begin{array}{l}\text { Número de } \\
\text { folhas }\end{array}$ & 230,182139 & 5,377 \\
\hline Altura $(\mathrm{cm})$ & 155,968502 & 3,6434 \\
\hline
\end{tabular}

${ }^{1} \mathrm{Sj}$ : contribuição da variável x para o valor da distância de Mahalanobis entre os cultivares $i$ e $i$ '
A análise de agrupamento pelo método de Tocher, baseada na matriz de Mahalanobis, separou os 10 genótipos em seis grupos distintos (TAB. 3). A formação desses grupos representa uma valiosa informação na escolha de genitores dentro de um programa de melhoramento, pois, segundo Bertan et al. (2006), as novas combinações híbridas a serem estabelecidas devem ser embasadas na magnitude de suas dissimilaridades.

Tabela 3 - Agrupamento baseado em caracteres morfológicos, pelo método de Tocher, de 10 genótipos de arroz cultivados in vitro, durante 21 dias, em meio MS, acrescido de $136 \mathrm{mM}$ de $\mathrm{NaCl}$

\begin{tabular}{cc}
\hline Grupos & Genótipos \\
\hline 1 & BR IRGA 418; Oro \\
2 & Moti; BRS Talento \\
3 & BRS Colosso; BR IRGA 410 \\
4 & BR IRGA 416, BRS Bojuru \\
5 & BR IRGA 409 \\
6 & BR IRGA 417 \\
\hline
\end{tabular}

O grupo 1 abrangeu 2 genótipos, BR IRGA 418 e Oro, os quais apresentaram a menor dissimilaridade encontrada na matriz de Mahalanobis, $\mathrm{D}^{2}=3,90$. Estes genótipos apresentaram comportamento semelhante para as variáveis massa fresca da parte aérea e do sistema radicular. Para a primeira variável foram observadas reduções de $38 \%$ e $41 \%$, para BR IRGA 418 e Oro, respectivamente. No que diz respeito à massa fresca do sistema radicular, BR IRGA 418 apresentou redução de $46 \%$, enquanto Oro apresentou a segunda maior percentagem de redução, $54 \%$, ficando atrás somente de Moti, com 59\% (TAB. 4).

Os genótipos Moti e BRS Talento formaram o segundo grupo e apresentaram dissimilaridade média de $\mathrm{D}^{2}=16,42$. Ambos pertencem ao grupo japônica e apresentaram comportamento semelhante para os caracteres número de raízes, massa fresca da parte aérea e do sistema radicular, sendo observados, no genótipo Moti, os maiores valores percentuais de redução para a maioria das variáveis.

O percentual de desempenho relativo observado nos genótipos IRGA 418, Oro e Moti, pertencentes aos grupos 1 e 2, indicam sensibilidade destes genótipos ao estresse salino e que os possíveis cruzamentos com essas cultivares diminuem a possibilidade de obtenção de genótipos superiores. 
Tabela 4 - Percentual de desempenho relativo de 10 genótipos de arroz cultivados in vitro, durante 21 dias, em meio MS, acrescido de $136 \mathrm{mM}$ de $\mathrm{NaCl}$ quando comparados ao tratamento-controle $(0 \mathrm{mM})$

\begin{tabular}{|c|c|c|c|c|c|c|c|c|c|c|c|c|}
\hline \multicolumn{13}{|c|}{ Desempenho Relativo (\%) } \\
\hline \multirow{2}{*}{ Genótipos** } & \multicolumn{2}{|c|}{-----Altura----- } & \multicolumn{2}{|c|}{---No Folhas--- } & \multicolumn{2}{|c|}{--Comp. Raiz-- } & \multicolumn{2}{|c|}{----No Raiz---- } & \multicolumn{2}{|c|}{-----MFPA----- } & \multicolumn{2}{|c|}{-----MFSR----- } \\
\hline & $0 *$ & 136 & $0^{*}$ & 136 & $0 *$ & 136 & $0 *$ & 136 & $0 *$ & 136 & $0 *$ & 136 \\
\hline 1 & 7,80 & -13 & 3,33 & -5 & 4,51 & +43 & 4,33 & -13 & 0,109 & -21 & 0,051 & -38 \\
\hline 2 & 7,10 & -39 & 5,40 & -24 & 5,28 & +29 & 5,67 & -46 & 0,106 & -31 & 0,049 & -32 \\
\hline 3 & 7,81 & -34 & 4,56 & -25 & 8,20 & +20 & 5,78 & -73 & 0,129 & -53 & 0,061 & -59 \\
\hline 4 & 10,23 & -31 & 4,56 & -24 & 5,03 & +18 & 8,06 & -17 & 0,105 & -38 & 0,048 & -46 \\
\hline 5 & 8,96 & -30 & 4,67 & -15 & 5,19 & +15 & 10,50 & -51 & 0,087 & -44 & 0,046 & -46 \\
\hline 6 & 7,32 & -13 & 4,22 & +3 & 6,48 & +9 & 4,72 & -15 & 0,093 & -29 & 0,041 & -18 \\
\hline 7 & 10,66 & -12 & 4,22 & -18 & 6,53 & +32 & 5,11 & -8 & 0,150 & -41 & 0,109 & -54 \\
\hline 8 & 8,33 & -49 & 3,33 & +15 & 5,70 & -1 & 5,17 & -41 & 0,097 & -22 & 0,051 & -43 \\
\hline 9 & 9,86 & -16 & 3,89 & -11 & 7,14 & -6 & 5,22 & -14 & 0,084 & -33 & 0,063 & -27 \\
\hline 10 & 8,14 & -42 & 3,44 & -12 & 6,79 & -21 & 5,78 & -53 & 0,085 & -52 & 0,047 & -56 \\
\hline
\end{tabular}

*Valor absoluto encontrado no tratamento controle. (+) Aumento e (-) redução relativa, tomando como referencial o valor absoluto do tratamentocontrole (100\%).**BRS Colosso (1), BR IRGA 416 (2), Moti (3), BR IRGA 418 (4), BR IRGA 417 (5), BR IRGA 410 (6), Oro (7), BR IRGA 409 (8), BRS Bojuru (9), BRS Talento (10)

De acordo com Cruz e Regazzi (2004), devese evitar a escolha de indivíduos de mesmo padrão de dissimilaridade nos cruzamentos, de modo a não restringir a variabilidade genética e, assim, evitar reflexos negativos nos ganhos a serem obtidos pela seleção. Desta forma, o cruzamento entre os genótipos Moti e Talento seria o menos indicado para obtenção de genótipos tolerantes à salinidade, pois sabe-se que, as melhores combinações híbridas a serem testadas em um programa de melhoramento devem envolver parentais tanto divergentes como de elevada performance média.

No grupo três foram inseridos os genótipos BRS Colosso e BR IRGA 410 que apresentam dissimilaridade média de $\mathrm{D}^{2}=18,31$. Nestes genótipos são observadas algumas das melhores repostas para o desempenho relativo referente aos caracteres altura, (13\% de redução), número de folhas, número de raízes e massa fresca da parte aérea e massa fresca do sistema radicular, indicando serem os mais tolerantes à salinidade.

De acordo com o desempenho relativo frente ao estresse, os genótipos BRS Colosso, BRS Bojuru e BR IRGA 410 apresentaram os melhores resultados, sendo, portanto, os mais tolerantes à salinidade na concentração de $136 \mathrm{mM}$ e, desta forma, os mais indicados para obtenção de êxitos em cruzamentos que visem esse caráter. Por outro lado, Moti apresentou as maiores reduções para os caracteres número de raiz e massa fresca da parte aérea e do sistema radicular, mostrando-se um genótipo sensível à salinidade. Assim, seria o menos indicado para combinações híbridas, uma vez que a escolha dos genótipos para novos cruzamentos devem ser baseadas também no seu potencial agronômico.

No quarto grupo estão BRS Bojuru e BR IRGA 416, com dissimilaridade média de $\mathrm{D}^{2}=19,55$. Os genótipos BR IRGA 417 e BR IRGA 409 ficaram em grupos separados e independentes, formando o quinto e sexto grupo, respectivamente.

Como se pode observar, o método de agrupamento de Tocher, aqui utilizado, foi eficiente em discriminar as cultivares quanto à diversidade para tolerância ao sal, de forma que a cultivar mais tolerante (BRS Colosso) e a mais sensível (Moti) foram as mais divergentes pela distância de Mahalanobis e agruparam-se separadamente, enquanto as mais similares, BR IRGA 418 e Oro, permaneceram no mesmo grupo.

A importância relativa das variáveis canônicas foi medida pela percentagem de seus autovalores (variâncias) em relação ao total dos autovalores, ou seja, é a porcentagem da variância total que elas explicam. Os valores da análise de variáveis canônicas, obtidos da matriz de correlação dos caracteres avaliados, revelaram que as duas primeiras variáveis canônicas foram suficientes para explicar $91,27 \%$ da variação observada. A primeira variável canônica absorveu $84,58 \%$ da variação obtida, tendo sido as características com maior contribuição as massas frescas da parte aérea e do sistema radicular, e as variáveis que menos contribuíram, a altura da parte aérea e comprimento de raiz. A segunda variável canônica absorveu $6,69 \%$ da variação entre os genótipos e os caracteres de maior 
peso foram comprimento de raiz e número de raízes (TAB. 5).

As importâncias relativas dos caracteres morfológicos nas variáveis canônicas podem ser conferidas na Tabela 6. Quanto maior o valor, maior peso tem a característica naquela variável canônica.

Conforme Cruz et al. (2004), para uma interpretação satisfatória da variabilidade encontrada entre os genótipos é necessário que as duas primeiras variáveis canônicas permitam estimativas mínimas de $80 \%$ da variação total contida no conjunto de caracteres. Devido ao fato das duas primeiras variáveis canônicas terem explicado mais de $80 \%$ da variância total de caracteres analisados $(91,27 \%$ da variância total acumulada) é possível explicar de maneira satisfatória a variabilidade manifestada entre os genótipos considerados nesta avaliação, permitindo representá-las em um gráfico de dispersão bidimensional.

A Figura 1 representa a dispersão gráfica no espaço bidimensional dos 10 genótipos em estudo, utilizando-se a primeira e a segunda variáveis canônicas.

Os grupos formados por meio da dispersão gráfica dos escores (FIG. 1) seguem a mesma tendência dos grupos



Figura 1 - Gráfico de dispersão de 10 genótipos de arroz cultivados in vitro em relação aos escores das duas primeiras variáveis canônicas (VC1 e VC2). BRS Colosso (1), BR IRGA 416 (2), Moti (3), BR IRGA 418 (4), BR IRGA 417 (5), BR IRGA 410 (6), Oro (7), BR IRGA 409 (8), BRS Bojuru (9), BRS Talento (10)

obtidos pelo método de otimização de Tocher (TAB. 3), fortalecendo, desta forma, os dados obtidos pela técnica de agrupamento e pela matriz de dissimilaridade.

Tabela 5 - Variâncias, variâncias percentuais e acumulada das variáveis canônicas obtidas de 10 genótipos de arroz cultivados in vitro, em meio MS, acrescido de $136 \mathrm{mM}$ de $\mathrm{NaCl}$

\begin{tabular}{crcc}
\hline \multirow{2}{*}{ Variáveis Canônicas } & \multicolumn{3}{c}{ Variância } \\
\cline { 2 - 4 } & Autovalores & Percentual & Percentual Acumulado \\
\hline 1 & 40,230859 & 84,581226 & 84,581226 \\
2 & 3,184731 & 6,695567 & 91,276793 \\
3 & 2,375844 & 4,994967 & 96,27176 \\
4 & 1,388153 & 2,918449 & 99,190209 \\
5 & 0,285823 & 0,600913 & 99,791121 \\
6 & 0,099353 & 0,208879 & 100,0 \\
\hline
\end{tabular}

Tabela 6 - Importância relativa dos caracteres morfológicos em cada variável canônica

\begin{tabular}{crrrrrr}
\hline \multirow{2}{*}{ Variável Canônica (VC) } & \multicolumn{7}{c}{ Caracteres Morfológicos* } \\
\cline { 2 - 7 } & \multicolumn{1}{c}{ AP } & NF & \multicolumn{1}{c}{ CR } & \multicolumn{1}{c}{ NR } & MFPA & \multicolumn{1}{c}{ MFR } \\
\hline VC 1 & 0,2823 & 0,6526 & 0,4727 & 0,6458 & 1,0375 & 0,7612 \\
VC 2 & 0,0750 & $-0,2896$ & 0,6708 & 0,6297 & $-0,2798$ & $-0,0928$ \\
VC 3 & 0,5926 & 0,0772 & $-0,3971$ & 0,0971 & $-0,3066$ & 0,6144 \\
VC 4 & 0,2548 & 0,1577 & 0,6491 & $-0,5631$ & $-0,1659$ & 0,6690 \\
VC 5 & 0,8451 & 0,4074 & $-0,1741$ & $-0,3539$ & 0,1102 & $-0,3344$ \\
VC 6 & $-0,2536$ & 0,8405 & 0,3106 & 0,2176 & $-0,2595$ & 0,1084 \\
\hline
\end{tabular}

* AP (altura da parte aérea), NF (número de folhas), CR (comprimento de raiz), NR (número de raiz), MFPA (massa fresca da parte aérea), MFR (massa fresca de raiz) 
Assim como neste trabalho, inúmeros outros, com diferentes espécies, têm comprovado que a análise da divergência genética através de procedimentos multivariados, como a distância generalizada de Mahalanobis, o método de agrupamento de otimização de Tocher e a dispersão gráfica das variáveis canônicas, concordantes entre si, é eficiente na discriminação de genótipos. Ao avaliar a divergência genética entre acessos de Capsicum spp., Sudré et al. (2006) confirmaram a eficiência de análises multivariadas na análise da variabilidade genética entre os diferentes acessos; Coimbra et al. (2010) realizaram a caracterização e divergência genética de populações de milho do Sudeste de Minas Gerais e Bertini et al. (2010), estudando a divergência genética entre genótipos de coentro, também obtiveram sucesso ao utilizar variáveis multicategóricas na discriminação de genótipos, bem como Campos et al. (2010) ao quantificar a divergência genética entre acessos de mandioca. Estas evidências experimentais comprovam que as análises multivariadas são eficientes para discriminar os indivíduos, geneticamente, permitindo agrupá-los de tal forma que exista homogeneidade dentro do grupo e heterogeneidade entre grupos.

\section{Conclusão}

Os métodos de otimização de Tocher e dispersão gráfica das variáveis canônicas são concordantes entre si, seguindo a mesma tendência de agrupamento dos genótipos. As características massa fresca da parte aérea, massa fresca de raiz e número de raízes são as que mais contribuem para dissimilaridade genética, existindo variabilidade para tolerância à salinidade entre os 10 genótipos de arroz testados. Os genótipos BRS Colosso, BRS Bojuru e BR IRGA 410 são os mais promissores para cruzamentos e obtenção de progênies superiores quanto à tolerância ao sal, enquanto o genótipo Moti é o menos indicado por apresentar sensibilidade ao excesso de sal.

\section{Referências}

AMORIN, A. V. et al. Respostas fisiológicas de plantas adultas de cajueiro anão precoce à salinidade. Revista Ciência Agronômica, v. 41, n. 01, p. 113-121, 2010.

BISSANI, C. A., GiAnelo, C., CAMARGO, F. A. O., TEDESCO, M. J. Fertilidade dos solos e manejo da adubação de culturas. 2. Ed. Porto Alegre: Editora Metrópole, 2008. 344p.

BENITEZ, L. C. et al. Tolerância à salinidade avaliada em genótipos de arroz cultivados in vitro. Revista Ceres, v. 57, n. 03 , p. $330-337,2010$.
BERTAN, I. et al. Dissimilaridade genética entre genótipos de trigo avaliados em cultivo hidropônico sob estresse por alumínio. Bragantia, v. 65, n. 01, p. 55-63, 2006.

BERTINI, C. H. M. et al. Análise multivariada e índice de seleção na identificação de genótipos superiores de feijão-caupi. Acta Scientiarum Agronomy, v. 32, n. 04, p. 613-619, 2010.

BERTINI, C. H. M. et al. Desempenho agronômico e divergência genética entre genótipos de coentro. Revista Ciência Agronômica, v. 41, n. 03, p. 409-416, 2010.

BEZERRA NETO, F. V. B. Descritores quantitativos na estimativa da divergência genética entre genótipos de mamoneira utilizando análises multivariadas. Revista Ciência Agronômica, v. 41, n. 02, p. 294-299, 2010.

CAMPOS, A. L. de. et al. Avaliação de acessos de mandioca do banco de germoplasma da UNEMAT Cáceres - Mato Grosso. Revista Trópica - Ciências Agrárias e Biológicas, v. 04, n. 02, p. 44-54, 2010.

COIMBRA, R. R. et al. Caracterização e divergência genética de populações de milho resgatadas do Sudeste de Minas Gerais. Revista Ciência Agronômica, v. 41, n. 01, p. 159-166, 2010

COMPANHIA NACIONAL DE ABASTECIMENTO (CONAB). Acompanhamento da safra brasileira: Grãos - Safra 2008/2009 - Terceiro levantamento. Brasília: Conab, 2008. 37 p. Disponível em <www.conab.gov.br/conabweb/download/safra/ estudo_safra.pdf $>$. Acesso em 01 mar. 2010.

CRUZ, C. D. Programa Genes: Aplicativo computacional em genética e estatística. Versão Windows - 2007, Viçosa, UFV.

CRUZ, C. D.; CARNEIRO, P. C. S. Modelos Biométricos Aplicados ao Melhoramento Genético. Viçosa: Editora UFV, 2003. $585 \mathrm{p}$.

CRUZ, C. D., REGAZZI. Modelos biométricos aplicados ao melhoramento genético. Viçosa: Editora UFV, 2004. 480 p.

MACEDO,V. R. M. et al. Salinidade na cultura do arroz no Rio Grande do Sul. Divisão de Pesquisa Estação Experimental do Arroz Equipe de Solos e Águas. Disponível em www.irga. gov.br>. Acesso em 13 jul. 2010.

MARCONDES, J., GARCIA, A. B. Aspectos citomorfológicos do estresse salino em plântulas de arroz (Oryza sativa L.). Arquivos do Instituto Biológico, v. 76, n. 02, p. 187-194, 2009.

MOREIRA, R. M. P et al. Potencial agronômico e divergência genética entre genótipos de feijão-vagem de crescimento determinado. Semina: Ciências Agrárias, v. 30, suplemento 1, p. 1051-1060, 2009.

MUNNS, R. Comparative physiology of salt and water stress. Plant, Cell and Environment, v. 25, p. 239-250, 2002.

MURASHIGE, T.; SKOOG, F. A revised medium for rapid growth and bioassays with tabacco tissue culture. Physiologia Plantarum, v. 15, p. 473-497, 1962.

OLIVEIRA, F. J et al. Divergência genética entre cultivares de caupi. Pesquisa Agropecuária Brasileira, v. 38, n. 05, p. 605-611, 2003. 
RAO, R. C. Advanced statistical methods in biometric research. New York: John Wiley \& Sons, 1952. 390p.

SINGH, D. The relative importance of characters affecting genetic divergence. The Indian Journal of Genetic and Plant Breeding, v. 36, p. 237-245, 1981.
SUDRÉ, C. P. et al. Variáveis multicategóricas na determinação da divergência genética entre acessos de pimenta e pimentão. Horticultura Brasileira, v. 24, n. 01, p. 88-93, 2006.

SZABOLCS, I. Salt-affected soils. Flórida: Library of Congress, 1989. 274p. 